\title{
Studies of Some Novel Chromium Pyridine Dicarboxylate Complexes
}

\section{S. JAYPRAKASH CHAUHAN ${ }^{1}$, P. RAMESHCHANDRA PATEL ${ }^{1}$ and V. AJIT PANDYA ${ }^{2}$}

\author{
${ }^{1}$ Department of Chemistry, ${ }^{2}$ Department of Biochemistry, C.U.SHAH Science College, \\ Nr. Gujarat University, Ashram Road, Ahmedabad. Gujarat, India. \\ *Corresponding author E-mail: jschauhan2010@yahoo.com
}

http://dx.doi.org/10.13005/ojc/300435

(Received: September 05, 2014; Accepted: October 11, 2014)

\begin{abstract}
Chromium pyridine di-carboxylate complexes are synthesized from Chromium (III) with pyridine 2, 6- dicarboxylic acid, pyridine 2, 3 and 2, 5- dicarboxylic acids. Chromium forms colored complexes. Chromium (III) forms a violate complex with pyridine 2, 6- dicarboxylic acid and purple violate complex with pyridine 2, 3 and 2,5- dicarboxylic acids. The job's method indicates metal ligand ratio to be 1:2. The interpretation of UV-VIS spectra indicates octahedral geometry and IR spectra give clue about the presence of Metal - Nitrogen and Metal- Oxygen bond. We have also made an effort to compare the spectrum of all the three complexes.
\end{abstract}

Key words: Chromium (III) Complex, pyridine dicarboxylic acids, Job's method, spectra.

\section{INTRODUCTION}

There are mainly six isomers of pyridine dicarboxylic acid. They are pyridine 2, 3-, 2, 4-, 2, 5, 2, 6-, 3, 4- and 3, 5- dicarboxylic acid. They show different modes of co-ordination with metal ions. Pyridine 2, 6- dicarboxylic acid which is known as dipicolinic acid is a well known $\mathrm{N}, \mathrm{O}$ chelator in coordination chemistry due to its diverse coordination modes ${ }^{1-5}$.

Dipicolinic acid is found to be present in natural compounds that show various biological functions and potential pharmacological activities. Pyridine 2, 3- dicarboxylic acid is known as quinolinic acid. Quinolinic acid is a product of Kynurenine path way, which metabolizes the amino acid tryptophan. It acts as an NMDA receptor agonist $^{6}$. (N-methyl-d-aspartate receptor).

The quinolinic acid which is derived from the amino acid tryptophan can be neurotoxin at high levels. Quinolinic acid can over stimulate nerve cells, causing the cells to die. Brain toxicity due to this acid has been implicated in Alzheimer's disease, autism, Huntington's disease, stroke, dementia, depression, HIV - associated dementia and schizophrenia. Fe (II) is reported to form a coordination compound with quinolinic acid ${ }^{7}$. 
Pyridine 2, 5- dicarboxylic acid is known as isocinchomeronic acid. Metal pyridinedicarboxylates have interesting properties in biological systems and their presence seems to be related with metal transport and cell membrane protection in some microorganisms.

We know that chromium activate enzymes. It is known to maintain protein stability and it speed up carbohydrate metabolism. It is reported that organic chromium (III) sources have shown to enhance the availability of chromium ${ }^{8}$.

A number of $\mathrm{Cr}$ - (dipic) ${ }_{2}$ complexes have been prepared and reported in these years ${ }^{9}$.

The chromium (III) - quinolinato complexes $\left[\mathrm{Cr}(\text { QuinH })_{3}\right)^{+3},\left[\mathrm{Cr}(\text { QuinH })_{2}\left(\mathrm{H}_{2} \mathrm{O}\right)_{2}\right]^{+}$and [Cr (quin $\left.\mathrm{H})\left(\mathrm{H}_{2} \mathrm{O}\right)_{4}\right]^{2+}$ have been obtained and characterized in solution ${ }^{10}$.

We have developed a method for the spectrophotometric determination of $\mathrm{Mn}$ (II) by pyridine2,6 dicarboxylic acid ${ }^{11}$.Synthesis characterizations and spectrophotometric determination of $\mathrm{Ni}(\mathrm{II})$ by pyridine2,3 and 2,5 dicarboxylic acid has also been studied ${ }^{12,13}$. Synthesis, characterization, antimicrobial studies and spectrophotometric determination of $\mathrm{Mn}$ (II) by pyridine2,3 dicarboxylic acid has been done ${ }^{14}$. In continuation of this work, we have synthesized a complex of chromium (III) with pyridine 2, 6 dicarboxylic acids in aqueous medium. We have carried out its solution studies and characterization by UV-VIS and FTIR spectroscopy. We have also prepared a complex of $\mathrm{Cr}$ (III) with pyridine 2, 3dicarboxylic acid as per the method reported and carried out its solution studies. The electronic spectra of complex $\left[\mathrm{Cr} \text { (dipic) }{ }_{2}\right]^{+1}$ are in agreement with the spectrum of the complex reported ${ }^{15}$.Similarly, we have synthesized a complex of $\mathrm{Cr}$ (III) with pyridine2, 5dicarboxylic acid and carried out its solution studies and characterization by UV-VIS and FTIR spectroscopy. We have also made an effort to compare the spectrum of all the three complexes.

\section{EXPERIMENTAL}

An UV-VIS Spectrometer - 108 equipped with $1 \mathrm{~cm}$ quartz cell was used for spectrophotometric measurement. The $\mathrm{pH}$ measurements were made with an Eli co LI- 120 $\mathrm{pH}$ meter. The FTIR spectra were recorded in Vaibhav Analytical Laboratories. The Jobs method of continuous variation was used to determine the metal ligand ratio.

The reagents used were pyridine 2, 6 dicarboxylic acid, pyridine 2, 3 and pyridine 2, 5 dicarboxylic acids. These substances were dissolved in minimum amount of $\mathrm{NaOH}$ and its sodium salt solution was used.

$\mathrm{Cr}$ (III) solution: - A $0.01 \mathrm{M}$ stock solution of $\mathrm{CrCl}_{3} .6 \mathrm{H} 2 \mathrm{O}$ prepared by dissolving in distilled water and was made acidic by adding dil $\mathrm{HCl}$. The $\mathrm{pH}$ was maintained by adding dil. $\mathrm{NaOH}$ and dil. $\mathrm{HCl}$.

\section{Procedure}

In each set of different $50 \mathrm{ml}$ standard flask, various volumes of $\mathrm{Cr}$ (III) and reagent solution were taken, the $\mathrm{pH}$ was maintained to 5.0 to 5.5 for $\mathrm{Cr}$ (III) -2, 6 PDC complex, 4.0 to 6.0 for $\mathrm{Cr}$ (III) - 2, 3 PDC complex, 3.5 to 4.5 for $\mathrm{Cr}$ (III)-2,5 PDC complex and absorbance was measured at $560 \mathrm{~nm}, 505 \mathrm{~nm}$ and $515 \mathrm{~nm}$ respectively.

Synthesis of the complex:

\section{[A] Synthesis of $\mathrm{Cr}$ (III) - 2, 6 PDC complexes}

$10 \mathrm{ml}$ of $0.01 \mathrm{M} \mathrm{Cr}$ (III) solution was taken in a container. To this solution $20 \mathrm{ml}$ of $0.01 \mathrm{M}$ dipicolinate (Sodium salt) was added. A pink violate colored complex is obtained in five minutes of time. The $\mathrm{pH}$ of the mixed solution was maintained in between 5.0 to 5.5. The complex precipitate out in the $\mathrm{pH}$ range 3.0 to 3.5 . The complex easily separates out if both the reagent solutions are concentrated. The pink colored precipitates obtained in the solution were filtered, washed and dried and FTIR study was carried out.

\section{Synthesis of $\mathrm{Cr}$ (III) - 2, 3 PDC complexes.}

$1 \mathrm{gm}$ of $\mathrm{CrCl}_{3} \cdot 6 \mathrm{H}_{2} \mathrm{O}$ was taken in a container and dissolved in distilled water. 2 grams quinolinic acid was dissolved in minimum amount of sodium hydroxide soln. The quinolinate solution was mixed with $\mathrm{Cr}$ (III) solution and $\mathrm{pH}$ was maintained in between 4 . 0 to 6.0. The $\mathrm{pH}$ was maintained around 3.0 and solution was kept for 12 hours. A red pink colored complex was obtained. 
The complex precipitates in the $\mathrm{pH}$ range 2.5 to 3.5. The solution was stirred for complete precipitation, filtered and dried. FTIR spectra were recorded.

\section{Synthesis of $\mathrm{Cr}$ (III) - 2, 5 PDC complex.}

$10 \mathrm{ml}$ of $0.01 \mathrm{M} \mathrm{Cr}$ (III) solution was taken in a container. To this solution $20 \mathrm{ml}$ of $0.01 \mathrm{M}$ isocinchomeric acid solution, prepared by dissolving the acid in minimum amount of $\mathrm{NaOH}$ was added. A Reddish pink color is obtained in the $\mathrm{pH}$ range 3.5 to 4.5 . Now the solution is made acidic i.e. $\mathrm{pH}$ is maintained in between 2.0 to 3.5 . The solution is stirred for about $1 \mathrm{hr}$ and kept for $24 \mathrm{hrs}$. Pink colored precipitates are obtained. They are washed with distilled water and dried. The FTIR was recorded.

\section{RESULTS AND DISCUSSIONS}

\section{Determination of $\lambda$ of the complexes.}

The absorption spectra of colored complex solution were recorded in the wave length region of $340-700 \mathrm{~nm}$. It was observed that the complex of $\mathrm{Cr}$ (III) $-2,6$ PDC showed the maximum absorbance at $560 \mathrm{~nm}$. The pink colored complex of $\mathrm{Cr}$ (III) $-2,3$ PDC showed the maximum absorbance at $505 \mathrm{~nm}$ $(\mathrm{pH}=4$ to 6$)$ where as the pink colored complex of $\mathrm{Cr}$ (III) $-2,5$ PDC showed maximum absorption at 515 nm. Refer to the Fig -1-3.

\section{Job's method}

The composition of the complexes was determined by Job's method. The following ratio of the complex was determined.

(a) The $\mathrm{Cr}$ (III) - 2, 6 PDC complex ratio was found to be 1: 2 Fig -4 .

(b) The $\mathrm{Cr}$ (III) -2 , 3 PDC complex ratio was found to be 1:2 Fig - 5 .

(c) The $\mathrm{Cr}$ (III) - 2, 5 PDC ratio was found to be 1: 2 Fig - 6.

The proposed structures of $\mathrm{Cr}$ (III) complexes of pyridine 2, 6 dicarboxylate, pyridine 2, 3 dicarboxylate and pyridine 2, 5 dicarboxylate may be presented as

Interpretation of the Electronic spectra of Chromium (III) complexes

Most of the chromium complexes are

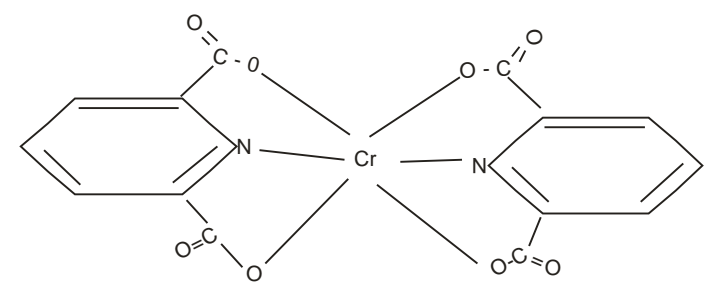

Scheme 1:

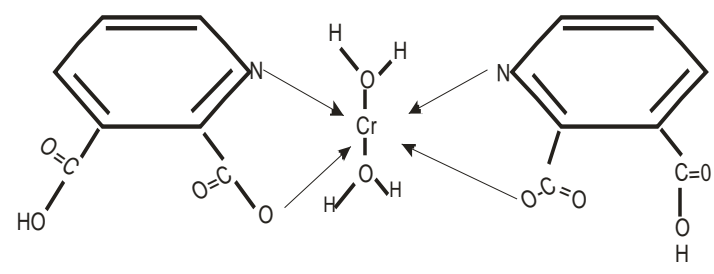

Scheme 2:

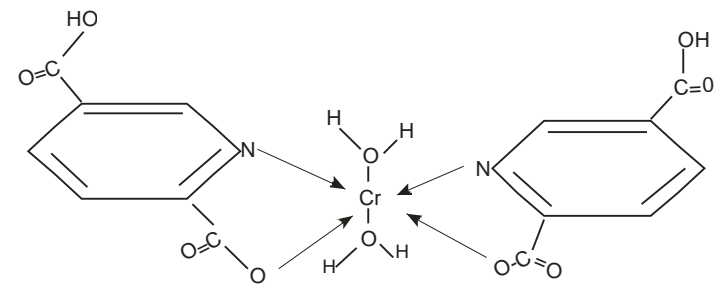

Scheme 3:

octahedral or distorted octahedral. The octahedral $\mathrm{d}^{3}$ systems are stable. Most text books describe in generals the expected electronic transitions by orgel diagrams or Tanabe - Sugano diagrams ${ }^{16-25}$. We have used orgel diagrams to describe the high spin octahedral configurations. We observe 2 or 3 peaks in the electronic spectra of $d^{3}$ high spin octahedral (and also $d^{2}, d^{7}$ and $d^{8}$ ) complexes which further can be explained by electron - electron interactions.

By using the Russell - Saunders (LS) coupling scheme, these free ion configurations give rise to $\mathrm{F}$ ground states which in octahedral and tetrahedral fields are split into terms designated by the symbols $A_{2}(g), T_{2}(g)$ and $T_{1}(g)$. We have used the orgel diagram for the interpretation of spectra. 


\section{Orgel diagrams}

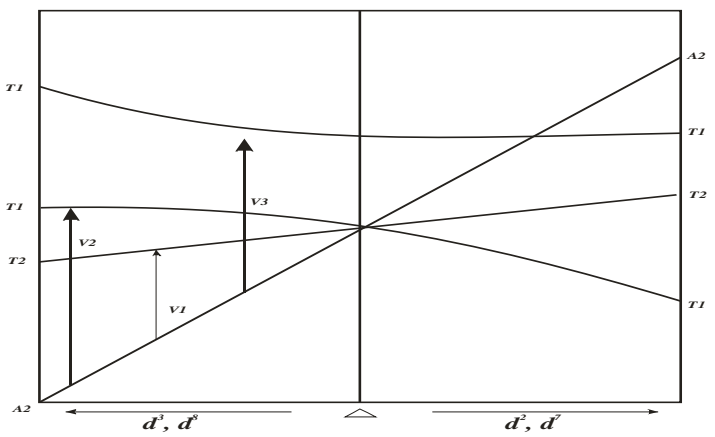

An orgel diagram showing the splitting of an $\mathrm{F}$ State is shown above. The lines showing the $A_{2}$ and $T_{2}$ terms are linear and depend only on ". The lines for the two $T_{1}$ terms are curved to obey the non-crossing rule. The left hand side is for $\mathrm{d}^{3} \mathrm{~d}^{8}$ octahedral complexes and the right hand side is for $d^{2} d^{7}$ octahedral complexes. For a $\mathrm{d}^{3}$ octahedral system, 3 peaks are predicted which results due to the follows transitions.

$$
\begin{array}{ll}
\text { 1. } & { }^{4} T_{2} g \leftarrow{ }^{4} A_{2} g . \\
\text { 2. } & { }^{4} T_{1} g(F) \leftarrow{ }^{4} A_{2} g \\
\text { 3. } & { }^{4} T_{1} g(p) \leftarrow{ }^{4} A_{2} g
\end{array}
$$

The following table illustrates the peak positions obtained from the absorption spectra of some octahedral $\mathrm{Cr}$ (III) complexes (in $\mathrm{cm}^{-1}$ ) ${ }^{26}$.

\begin{tabular}{lccc}
\hline COMPLEX & $v_{1}\left(\right.$ in $\left.\mathbf{~ c m}^{-1}\right)$ & $v_{2}\left(\right.$ in $\left.\mathbf{~ c m}^{-1}\right)$ & $v_{3}\left(\right.$ in $\left.\mathbf{~ c m}^{-1}\right)$ \\
\hline$\left[\mathrm{Cr}\left(\mathrm{C}_{2} \mathrm{O}_{4}\right)_{3}\right]^{3-}$ & 17544 & 23866 & Obscured \\
{$\left[\mathrm{Cr}(\mathrm{NCS})_{6}\right]^{3-}$} & 17800 & 23800 & Obscured \\
{$\left[\mathrm{Cr}(\mathrm{acac})_{3}\right]^{3-}$} & 17860 & 23800 & Obscured \\
{$\left[\mathrm{Cr}\left(\mathrm{NH}_{3}\right)_{6}\right]^{]^{3+}}$} & 21550 & 28500 & Obscured \\
{$\left[\mathrm{Cr}(\mathrm{en})_{3}\right]^{3+}$} & 21600 & 28500 & Obscured \\
$\left.\mathrm{Cr}(\mathrm{CN})_{6}\right]^{3-}$ & 26700 & 32200 & Obscured
\end{tabular}

\section{Electronic Spectra of $\mathrm{Cr}(\mathrm{III})$ - Pyridine} dicarboxylates

\section{$\mathrm{Cr}$ (III) - Pyridine 2, 6 dicarboxylate complex}

Looking at the $d^{3}$ octahedral case, three peaks can be predicted which would correrpond to the following transitions.
(1) $\quad{ }^{4} \mathrm{~T}_{2} \mathrm{~g} \leftarrow{ }^{4} \mathrm{~A}_{2} \mathrm{~g}$
(2) $\quad{ }^{4} \mathrm{~T}_{1} \mathrm{~g}(\mathrm{~F}) \leftarrow{ }^{4} \mathrm{~A}_{2} \mathrm{~g}$
(3) $\quad{ }^{4} \mathrm{~T}_{1} \mathrm{~g}(\mathrm{P}) \leftarrow{ }^{4} \mathrm{~A}_{2} \mathrm{~g}$

In the visible region the maximum absorption occurs at $560 \mathrm{~nm}$ (fig 1) which corresponds to $17857 \mathrm{~cm}-1$. This is due to ${ }^{4} \mathrm{~T}_{2} \mathrm{~g} \leftarrow$ ${ }^{4} \mathrm{~A}_{2} \mathrm{~g}\left(\mathrm{~V}_{1}\right)$ this corresponds to $\Delta_{0}$ (The frequency of the lowest energy transition provides the value of " o) The second peak occurs at $420 \mathrm{~nm}$ (i.e. 23800 $\mathrm{cm}-)$. This is due to ${ }^{4} \mathrm{Tig}(\mathrm{F}){ }^{4} \mathrm{~A}_{2} \mathrm{~g}$. The third peak is obscured by very intense charge transfer band.

\section{Vibration Studies}

The patterns of IR spectrum show vibrations due to dipicolinate ligands the $\mathrm{V}(\mathrm{O}-$ $\mathrm{H})$ vibrations belonging to the $\mathrm{H}_{3} \mathrm{O}^{+}$fragments are not observed as bands in the region 3599,3558 , 3474 and $3423 \mathrm{~cm}^{-1}$. Therefore the cation $\mathrm{H}_{3} \mathrm{O}^{+}$is absent. The stretching frequencies due to the aromatic rings at 3000 to $3100 \mathrm{~cm}^{-1}$ are found. In the IR spectrum of the complex, all the bands involving $\mathrm{O}-\mathrm{H}$ vibrations of the carboxyl ate are absent, namely the $\mathrm{O}-\mathrm{H}$ stretching of the $\mathrm{COOH}$ groups, the $\mathrm{C}-\mathrm{OH}$ in plane bonding and out of plane $\mathrm{O}-\mathrm{H}$ deformation mode, hence showing deprotonation of the $\mathrm{COOH}$ group and coordination to the metal ${ }^{27}$. The absorption bands in the region $650-780 \mathrm{~cm}^{-1}$ are attributed to the vibrations of the co-ordinate pyridine molecules.

The absence of IR bands around $1700 \mathrm{~cm}^{-1}$ indicates that al the $\mathrm{COOH}$ - carboxylic groups are deprotonated.

The frequency at 1600 , and $1651 \mathrm{~cm}^{-1}$ indicates the carbonyl frequency of the carboxyl group which is attached with the metal as. The metal - nitrogen $(\mathrm{M}-\mathrm{N})$ and metal - Oxygen $(\mathrm{M}-\mathrm{O})$ bonds were further confirmed by the presence of the band around $472 \mathrm{~cm}^{-1}$ and $542 \mathrm{~cm}^{-1}$. ${ }^{28-29}$

\section{Cr (III) - Pyridine 2, 3 dicarboxylate complex}

Looking at the $\mathrm{d}^{3}$ octahedral case, three peaks can be predicted which would corresponds to the following transitions.
(1) ${ }^{4} \mathrm{~T}_{2} \mathrm{~g} \leftarrow{ }^{4} \mathrm{~A}_{2} \mathrm{~g}$
(2) $\quad{ }^{4} \mathrm{~T}_{1} \mathrm{~g}(\mathrm{~F}) \leftarrow{ }^{4} \mathrm{~A}_{2} \mathrm{~g}$
(3) $\quad{ }^{4} T_{1} g(P) \leftarrow{ }^{4} A_{2} g$

In the visible region the maximum absorption occurs at $505 \mathrm{~nm}$ (fig 2) which corresponds to $20,200 \mathrm{~cm}-1$. This is due to ${ }^{4} \mathrm{~T}_{2} \mathrm{~g}{ }^{4} \mathrm{~A}_{2} \mathrm{~g}$ $\left(V_{1}\right)$ this corresponds to $\Delta_{0}$.The frequency of the lowest energy transition provides the value of $\Delta_{0}$. 
The second peak occurs at $415 \mathrm{~nm}$ (i.e. $25937 \mathrm{~cm}$ ). This is due to ${ }^{4} \mathrm{Tig}(\mathrm{F}){ }^{4} \mathrm{~A}_{2} \mathrm{~g}$. The third peak is obscured by very intense charge transfer band.

\section{Vibration Studies}

The spectra was recorded in the range $4000-400 \mathrm{~cm}^{-1}$. The IR spectra contained several

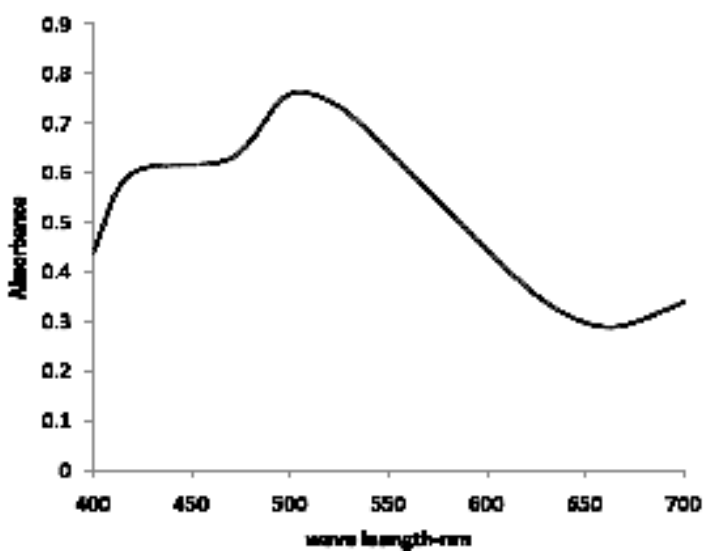

Fig. 1: Spectra of $\mathrm{Cr}(\mathrm{III})-2,6$ PDC complex

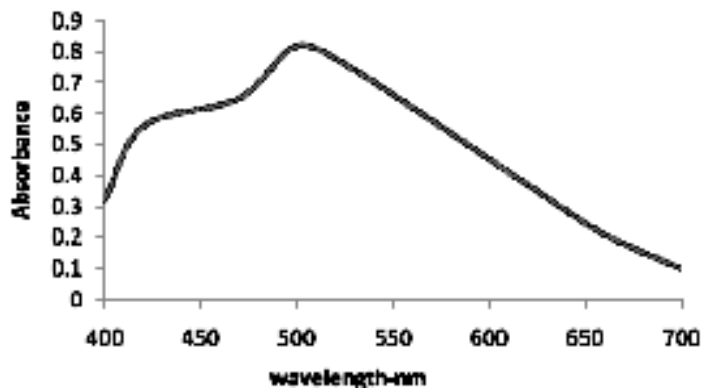

Fig. 3: Spectra of $\mathrm{Cr}(\mathrm{III})-2,5 \mathrm{PDC}$ complex

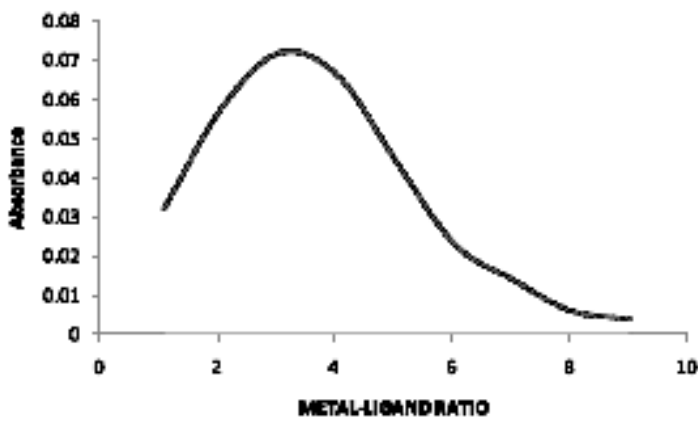

Fig. 5: Jobs method for $\mathrm{Cr}(\mathrm{III})-2,3 P D C$ complex indicative peaks such as an absorption band at 1400-1600 $\mathrm{Cm}^{-1}$ which refers to the stretching vibrations of $\mathrm{C}=0$ bond. The stretching frequencies due to the aromatic rings are found at $3000-3100$ $\mathrm{cm}^{-1}$. The frequencies around $1600-1630 \mathrm{~cm}^{-1}$ regions are due to $\mathrm{HOH}$ bending. The presence of $\mathrm{COO}^{-}$group is revealed by IR spectrum which

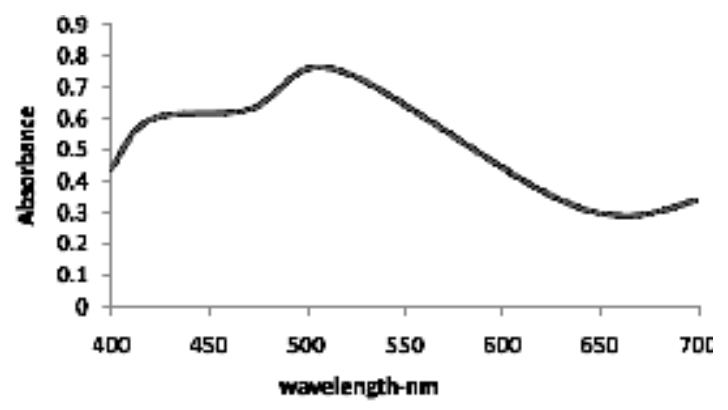

Fig 2: Spectra of $\mathrm{Cr}(\mathrm{III})-2,3$ PDC complex

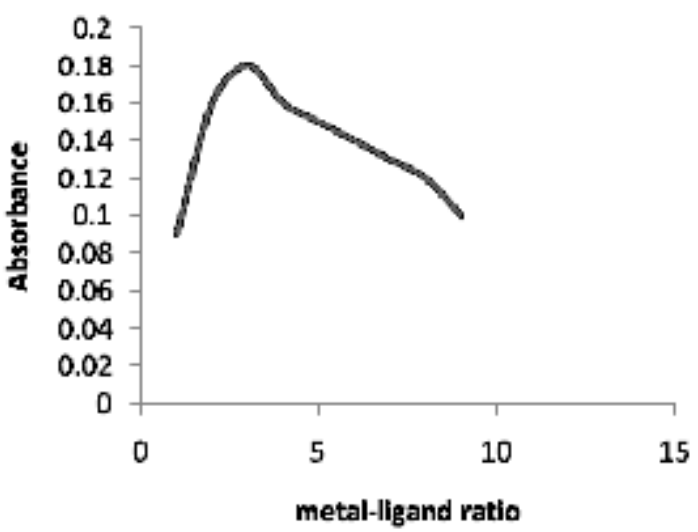

Fig. 4: Jobs method for $\mathrm{Cr}(\mathrm{III})-2,6 \mathrm{PDC}$ complex

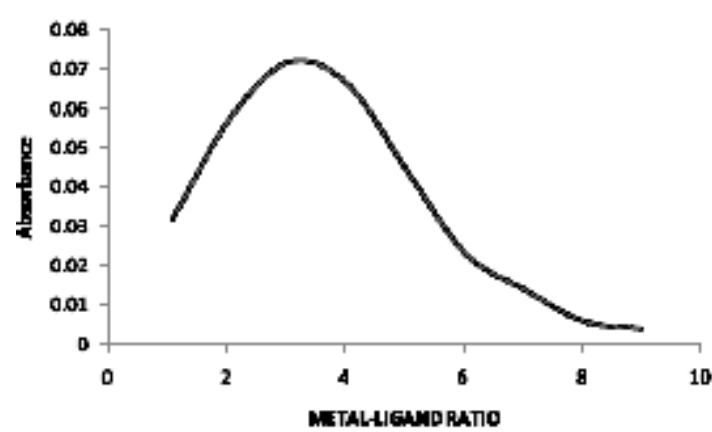

Fig. 6: Jobs method for $\mathrm{Cr}$ (III)-2,5PDC complex 
shows absorption bands at 1653 and $1400 \mathrm{~cm}^{-1}$ corresponding to ${ }_{\text {as }}\left(\mathrm{COO}^{-}\right)$and ${ }_{\mathrm{s}}\left(\mathrm{COO}^{-}\right)$vibrations. Predominant vibrations of isocinchomeric acid associated with $\mathrm{O}-\mathrm{H}$ are $2800 \mathrm{~cm}^{-1}\{\mathrm{v}(\mathrm{O}-\mathrm{H})\}, 1417$ $\mathrm{Cm}^{-1}\{\delta(\mathrm{O}-\mathrm{H})\}$ and $927 \mathrm{~cm}^{-1}\{\gamma(\mathrm{OH})\}$, which are absent indicating the deprotonation of $-\mathrm{COOH}$ group and coordination with the $\mathrm{Cr}(\mathrm{III})$. The absorption bands in the region $657-750 \mathrm{~cm}^{-1}$ are attributed to the vibrations of the coordinated pyridine molecules. The presence of IR bands around $1700 \mathrm{~cm}^{-1}$ indicates that all the $\mathrm{COOH}-$ carboxylic groups are not deprotonated.

The frequency at 1665 , and $1610 \mathrm{~cm}^{-1}$ indicates the carbonyl frequency of the carboxyl group which is attached with the metal as $\|_{-\mathrm{C}-\mathrm{O} \longrightarrow \mathrm{M}}^{\mathrm{O}}$. The metal - nitrogen $(\mathrm{M}-\mathrm{N})$ and metal - Oxygen ( $\mathrm{M}-\mathrm{O}$ ) bonds were further confirmed by the presence of the band around $650-450 \mathrm{~cm}^{-1}$ and $(570-400) \mathrm{cm}^{-1}$. ${ }^{28-29}$

\section{Cr (III) - Pyridine 2, 5 dicarboxylate complex} Looking at the $\mathrm{d}^{3}$ octahedral case, three peaks can be predicted which would corresponds to the following transitions.

(1) $\quad{ }^{4} \mathrm{~T}_{2} \mathrm{~g} \leftarrow{ }^{4} \mathrm{~A}_{2} \mathrm{~g}$

(2) $\quad{ }^{4} T_{1} g(F) \leftarrow{ }^{4} A_{2} g$

(3) $\quad{ }^{4} T_{1} g(P) \leftarrow{ }^{4} A_{2} g$

In the visible region the maximum absorption occurs at $515 \mathrm{~nm}$ (fig 3) which corresponds to $20,600 \mathrm{~cm}-1$. This is due to ${ }^{4} \mathrm{~T}_{2} \mathrm{~g}$ ${ }^{4} A_{2} g\left(V_{1}\right)$ this corresponds to $\Delta_{0}$. (The frequency of the lowest energy transition provides the value of " o. The second peak occurs at $420 \mathrm{~nm}$ (i.e. $23800 \mathrm{~cm}$ ). This is due to ${ }^{4} \mathrm{Tig}(\mathrm{F}){ }^{4} \mathrm{~A}_{2} \mathrm{~g}$. The third peak is obscured by very intense charge transfer band.

Vibration Studies : The spectra was recorded in the range $4000-400 \mathrm{~cm}^{-1}$. The IR spectra contained several indicative peaks such as an absorption band at $1400-1600 \mathrm{Cm}^{-1}$ which refers to the stretching vibrations of $\mathrm{C}=0$ bond. The stretching frequencies due to the aromatic rings are found around $3000-3100 \mathrm{~cm}^{-1}$. The frequencies around
$1590-1650 \mathrm{~cm}^{-1}$ regions are due to $\mathrm{HOH}$ bending. The presence of COO- group is revealed by IR spectrum which shows absorption bands at 1660 and $1450 \mathrm{~cm}^{-1}$ corresponding to (COO) and s (COO-) vibrations.

Predominant vibrations of isocinchomeric acid associated with $\mathrm{O}-\mathrm{H}$ are $2800 \mathrm{~cm}^{-1}\{(\mathrm{O}-\mathrm{H})\}$, $1417 \mathrm{Cm}^{-1}\{(\mathrm{O}-\mathrm{H})\}$ and $927 \mathrm{~cm}^{-1}\{(\mathrm{OH})\}$, which are absent indicating the deprotonation of $-\mathrm{COOH}$ group and coordination with the $\mathrm{Cr}(\mathrm{III})$. The absorption bands in the region $657-750 \mathrm{~cm}^{-1}$ are attributed to the vibrations of the coordinated pyridine molecules. The presence of IR bands around $1700 \mathrm{~cm}^{-1}$ indicates that all the $\mathrm{COOH}-$ carboxylic groups are not deprotonated.

The frequency at 1663 , and $1610 \mathrm{~cm}^{-1}$ indicates the carbonyl frequency of the carboxyl group which is attached with the metal as. The metal - nitrogen $(\mathrm{M}-\mathrm{N})$ and metal - Oxygen $(\mathrm{M}-\mathrm{O})$ bonds were further confirmed by the presence of the band around $650-450 \mathrm{~cm}^{-1}$ and $(570-400)$ $\mathrm{cm}^{-1} 28-29$.

\section{CONCLUSION}

Pyridine dicarboxylic acids are peculiar ligands. They shows different co-ordination modes. Therefore they may react differently with metals in different conditions. This has aroused a considerable interest in their studies. Different ways of synthesis of the complexes are also possible. Due to this reason we have made an effort to interpret the spectra of the chromium complexes. Interpretation of electronic spectra of chromiumpyridinedicarboxylate complexes indicates that they have either octahedral or distorted octahedral geometries.

\section{ACKNOWLEDGEMENTS}

The authors are thankful to C. U. Shah Science College for providing laboratory facilities. 


\section{REFERENCES}

1. M A Sharif, H Aghabozorg, A shokrollahi, M Shamsipur, A Moghimi and GK Ckelbick polish, J.Chem, 2006; 80: 847-863.

2. Z Aghajani, MA Sharif, $\mathrm{H}$ Aghabozorg, and A Nader pour, Acta Crystallogr 2006; 62: 830832.

3. M Chatterjee, M Maji, S Ghosh, TCW- Mak K Studies of V (111) complexes,. Chem. Soc., Dalton Trans. 1998; 21, 3641-3645.

4. LC Nathan, TD Mai. J. Chem. Cryst. 2000; 30: $509-518$.

5. LC Nathan. Trends Inorg. Chem. 1993; 3: 415 -435 .

6. Misztal M, Frankiewicz, Parsons CG, DanyszW. January 1996, Eur. J.Pharmacol, 296(1);1-8 Doi: 10.1016/0014-2999(95) 00682-6. PMID 8720470

7. A.K. Majumdar,S.P. Bag, Analytica Chemica Acta, ,1959, 21; 324-330

8. Ranjbar, M.; Aghabozorg,H.; Moghimi ,A.; Yanovsky,A.Z. Kristallogr. New Cryst.Struct. 2001, 216, 626.

9. Khaled Ghasemi, Ali Reza Rezvani, Bull. Korean Chem.Soc., 2013, 34(10),3093

10. Ewa Kita and Karin Golembiewska Department of Chemistry, N. Copernicus University, 87-100 Toruri, Poland. Transition metal chemistry 2007 32-56-63 Doi : 10.1007S11243-006-01288

11. Chauhan Jayprakash S, Pandya Ajit V; International Journal of Engineering and Science Invention, 2013, 2(2) (36-43),

12. Chauhan J. S., Pandya A. V. International Research Journal of Pharmaceutical and Applied Sciences 2013; 3(5) 31-36

13. Chauhan Jayprakash S, Pandya Ajit V; World Journal of Pharmaceutical Research,2014; 3(2) 2527-2541

14. Chauhan J. S, Pandya A. V.Asian Resonance; 1, Issue-V, Jan-2013

15. Gonzalez-Baro,A.C.; Pis-Diez,R.; E.Piro,O.E.; Parajon-Costa, B.S. Polyhedron-2008,
27,502

16. Basic Inorganic chemistry, F.A.Cotton, G.Wilkison and P.I.Gaus, $3^{\text {rd }}$ edition, John Wiley and Sons, Inc.New York, 1995.

17. Physical Inorganic Chemistry, S.F.A.Kettle, Oxford University Press, New York, 1998.

18. Complexes and First Raw Transition Elements, D.Nicholls, Macmillan Press Ltd, London 1971.

19. The Chemistry of the Elements, N.N.Greenwood and A.Earnshaw, Pergamon, Press, Oxford, 1984.

20. Concepts and Models of Inorganic Chemistry, B.E.Douglas, D.H.McDaniel and J.J.Alexender, $2^{\text {nd }}$ edition, John Wiley\& Sons, New York, 1983.

21. Inorganic Chemistry, J.A.Huheey, 3rd edition, Harper Row, New York, 1983.

22. Inorganic Chemistry, G.L.Meissler and. A. Tarr, 2nd edition, Prentice Hall, New Gercy, 1998.

23. Inorganic Chemistry, D.F.Shriver and P.W.Atkins, 3rd edition, W.H.Freeman, New York, 1999.

24. Basic Principles of Ligand Field Theory, H.L.Schlafer and G.Gilemann, WileyInterscience, New York, 1969.

25. Y.Tanabe and S.Sugano, J.Phys.Soc.Japan, 1954; 9, ,753 and766.

26. Prof.Robert John Lancashire, Department of Chemistry, University of West Indies, Mona Campus, Kingston 7, Jamaica.

27. , Lin-Vien, D.; Colthup, N.B.; Fately W.G.; Grassell, J.G., Infrared and Raman Characteristic Frequencies of Organic Molecules; Academic Press; Boston, 1991.

28. Krishan, B,; Prakash, O,; El-Mossalamy, E.H,; Orient. J.Chem. 2013, 29(1), 381-388.

29. Rrington, J.E. Microbial, Rev. 1993, 57, 1-33

30. Murkami, K. I Tnemura, y.i Yoshino, M. J. Nutr. Brioche. 2003, 14, 99-103. 